\title{
Turning it off: Emotions in Digital-Free Travel
}

\begin{abstract}
This article aims to theorize digitally disconnected travel experiences by investigating various emotional responses during the process of withdrawal and regain of technological affordances. The theoretical concepts of affordance and emotional episodes were adopted in this study to create a conceptual framework. Fifteen diaries and 18 interviews were collected from 23 participants' reflections of their disconnected experiences. This study thus contributes a contextual update of the emotional episode theory by providing a detailed account of various emotions in the entire disconnecting/reconnecting travel experience. Also, this study contributes to the affordance literature by exploring the fluidity of technology affordances and environmental affordances. This paper develops the Disconnected Emotions Model (DEM), a theoretical framework to provide an understanding of the changing relationship between human emotions and material affordances.
\end{abstract}

Keywords: digital-free travel, affordances, emotions, technology usage patterns, Disconnected Emotions Model 


\section{Introduction}

We live in a world of ubiquitous connectivity. Technology has altered and revolutionized the tourism landscape (Buhalis 2003, Neuhofer, Buhalis, and Ladkin 2014). The UK Gadget Habit Report (2017) found that people take 38\% more gadgets with them on holiday than they do during their daily life. It has been proven that the ubiquitous connectivity through technology to some extent distracts individuals from engaging with physical experiences (Tanti and Buhalis 2016) and may have a negative impact on tourists' consumptions of sounds and sights, wellbeing, social interactions, and experience of 'others' (Ayeh 2018). Tribe and Mkono (2017) suggested that the use of travel apps, such as TripAdvisor, could frustrate tourists who are searching for authenticity. In response to this, the idea of seeking to escape from ubiquitous connectivity has emerged. Tourism and hospitality products ranging from shorter experiences such as digital-free cafes and restaurants to longer experiences of 'disconnected holidays' and 'digital detox camps' have become popular.

Furthermore, tourism organizations such as VisitEngland and VisitScotland also addressed the digital detox trend, and the connection between wellness tourism and the efficient use of smartphones. The term 'digital-free tourism' (DFT) was proposed by Li, Pearce, and Low (2018) to describe tourism-related activities in locations with limited or no technology access. Individuals who choose to disconnect on holiday are looking for therapeutic rehabilitation (Paris et al. 2015) to achieve a positive outcome (Neuhofer and Ladkin 2017); however, the sudden withdrawal of technology might lead to negative emotions such as anxiety (O’Regan 2008) and tensions (Pearce and Gretzel 2012).

While we value the significance of technology and connectivity in tourism (Neuhofer, Buhalis, and Ladkin 2015, Neuhofer 2016, Navío-Marco, Ruiz-Gómez, and Sevilla-Sevilla 
2018), we also believe that an understanding of the implications of DFT (Li, Pearce, and Low 2018) is essential. Acknowledging that tourism studies were conducted long before the introduction of technologies, this study focuses on digitally disconnected travel experiences in the current ubiquitous connected world, where people are used to constant information access and various services provided by different applications (Dery, Kolb, and MacCormick 2014). Despite a growing desire amongst travelers to disconnect from technology during their holidays as a form of therapeutic rehabilitation (Paris et al. 2015), tourism literature discusses little about technology disconnection.

From our search in the tourism literature, only a few studies focus exclusively on DFT. Earlier research on disconnection focused on tourists being forced to disconnect in a 'technology dead zone', an area with no or poor connection where "the experience of being unplugged involves several strong sensory elements or more precisely the absence of highly familiar sensory inputs" (Pearce and Gretzel 2012, 39). Paris et al. (2015) discussed the anxiety and social tensions involved when disconnecting on holiday. Both studies asked participants to recall their disconnected experiences, and primarily focused on the negative consequences of being disconnected, and to a limited extent, positive outcomes.

Two years later, more disconnection research re-emerged. These studies tend to focus on the entire concept of connectivity, not specifically on dis-connectivity. For example, Dickinson, Hibbert, and Filimonau (2016) explored connectivity at the campsite, and the theme of disconnection only emerged from their empirical data analysis. They found that even though some tourists desire to be completely disconnected, it is not embraced by all tourists. Rosenberg (2019) also discovered the disconnection theme after surveying backpackers about their connected behavior. Tanti and Buhalis (2016) explored five consequences (e.g. communication) of being disconnected, and Neuhofer and Ladkin (2017) set a research agenda for connectivity research. Tribe and Mkono (2017) also presented a 
partial view of dis-connectivity through their conceptualization of 'e-lienation', and the negative consequences of technology.

From the literature, we identified four research gaps in disconnected tourism research. First, most studies collected empirical data about 'disconnection' by recruiting participants after their holidays and asked them to recall their 'connected' experiences. We argue it is essential that studies should engage in the whole disconnect process by recruiting and informing participants to capture the dynamics of emotions related to disconnection. Second, despite Germann Molz and Paris (2015), Paris et al. (2015) and Neuhofer and Ladkin (2017) calling for further research in travelers' disconnected experiences, there remains relatively sparse empirical research with few exceptions (see Paris et al. 2015, Pearce and Gretzel 2012). Recently, e-lienation (Tribe and Mkono 2017) and media discourse of DFT (Li, Pearce, and Low 2018) provide essential insights into this topic. However, the contextual understanding of tourists' perceptions and emotions should not be neglected.

Third, in the previous literature, the primary findings focused on negative emotions such as anxiety and tension (Paris et al. 2015), and that being 'unplugged', may be upsetting for some tourists and produces feelings of distress and anxiety (O'Regan 2008). The focus on positive outcomes, although present, is still sparse. Positive outcomes of DFT such as wellbeing and work-life balance had partially been discussed (e.g. Dickinson, Hibbert, and Filimonau 2016). Li, Pearce, and Low (2018) used secondary research to present some positive outcomes of DFT. We believe that the positive outcomes should be further empirically investigated as part of the complex and continuously evolving emotions within a broader context. Fourth, only Dickinson, Hibbert, and Filimonau (2016) collected empirical data in situ from various campsites in the UK, and Rosenberg (2019) in India. No other research on this topic named a location where participants disconnected. We argue that 
emotions are highly embedded in situated environments and cannot be extracted without considering the environmental and social context.

To address these research gaps, this study aims to understand the complexity and dynamics of emotions in highly disconnected settings by providing first-hand empirical narratives from participants who were voluntarily taking part and informed before the digitalfree experience. In detail, we examine the entire disconnect process from the pre-disconnect, disconnection, and reconnection phases to explore how people experience different emotions when they cannot rely on their mobile devices, and what the implications on their holiday experience are.

This paper will use two theoretical lenses. The first theoretical lens is the theory of affordance (Gibson 1977), which originated in the field of ecology to understand the potential behavior of animals enabled by the environment. Affordance theory has since been used in tourism literature (e.g. Rantala 2010) and has also been used to examine the affordances enabled by technologies (e.g. Leonardi 2013). In our analysis of previous disconnection research, the focus was on technology as a whole, rather than the finer grain lens of affordances (behaviors enabled by technology). The application of affordance responds to the calls for shifting from a human-centric focus to the neglected 'materialities' in tourism studies (Cohen and Cohen 2019, Haldrup and Larsen 2006).

Affordances in this study allow us to understand the loss or gain of technological opportunities when travelers engage in DFT. An affordance can be considered as the relationship between the human and a technological artifact (Zheng and Yu 2016), which enables opportunities for potential behaviors while using technology (Volkoff and Strong 2013). For example, Google Maps affords navigation. Affordances are useful for examining previously unrecognized roles of technology (Tim et al. 2017, Majchrzak and Markus 2012). 
The affordance lens allows us to understand not just the loss of a physical artefact (e.g. a mobile phone) during digital free tourism, but everything they can usually achieve with it (e.g. sending text messages, navigating).

The emotional episode (Zhang 2013) is chosen as the second theoretical lens. The theory is conceptualised to understand complex human emotional responses towards disconnection and reconnection of technology. Emotional episodes thus help to provide comprehensive explanations and understanding of the hybrid and dynamic emotional journey that digital-free travelers are experiencing. Although disconnected emotions were discussed in some studies (see Pearce and Gretzel 2012, Paris et al. 2015), the relationship between holistic emotional responses and the changes in affordances were overlooked. We argue that travelers experience various emotional reactions to changes in affordances as they transition between a connected state, to disconnected, and to re-connection. Therefore, in this study, we connect the complex emotional responses with the various situated conditions of affordances and emphasize their relational enactments throughout the digital-free experience.

This article aims to theorize the emotion-based disconnected experience. We propose that affordance changes and emotional episodes are two theoretical lenses useful for facilitating the understanding of digital-free experiences into four steps: a) emotional dependence of technological affordances in everyday life; b) emotional responses to technological affordance loss; c) emotional changes during the loss of technological affordances and gaining environmental affordances and social interactions; d) emotional responses to technological affordance regain. Therefore, our research question is: how do travelers experience emotions during the loss and regain of technological affordances?

In addition to providing a comprehensive understanding of the disconnected experience, this article also aims to contribute to the literature of affordance and emotions by 
linking them in a (dis)connected event. The paper is structured as follows. First, we review the literature about technology and (dis)connectivity research in tourism. Next, we present our theoretical lenses of emotional episodes and affordances, and our conceptual framework, followed by our methodological approach. We then present our findings, discussion, and theoretical model, followed by a conclusion. 


\section{Theoretical Development}

\subsection{Emotions and Technology}

Emotions research in the tourism literature is wide-reaching (Cohen, Prayag, and Moital 2014, Kim and Fesenmaier 2015). However, emotions and technology research in tourism is relatively limited. There are few tourism studies involving emotions as experienced through technology use in tourism. Robinson (2014) explored the emotions and choreography of the digital photograph using the concept of the tourist gaze to develop an emediated gaze. The emotional aspect of the analysis was discovered using computer generated word clouds. However, no emotion theories were employed. Lee and Jeong (2012) presented a conceptual study of flow experiences within the lodging industry. They developed eight propositions which incorporated some aspects of emotions. However, the main focus of their study was on flow theory. Therefore their findings placed emotions as only part of the overall experience of lodgers. Zakrisson and Zillinger (2012), used GPS data and questionnaires, to explore tourist emotions among different movement patterns of tourists. The authors tied 28 different emotion labels to locations and discovered that tourists differ with regards to what was considered a negative experience and how tourists responded emotionally to experiences. In these studies, although emotions were discussed, we found there is a lack of application of emotion theories. Also, in some studies, emotions are not the core focus, with emotional measures appearing as direct or indirect constructs within larger research models (see Huang et al. 2013, Lee, Jeong, and Jeon 2016, Karla and Cara 2016).

Based on the lack of theoretical approaches to emotions research based on technology use in tourism, we draw from the Information Systems (IS) field to fill this gap. IS researchers are advocating studies using emotion-based models of technology use (Beaudry and Pinsonneault 2010, Stein et al. 2015). Beaudry and Pinsonneault (2010) provided a 
summary of IS studies that have examined emotions. However, many of the studies examined only a single type of emotion, such as enjoyment, satisfaction, or pleasure. A smaller number of studies examined the concept of affect, which is a broader term used for a set of more specific concepts, including emotions, moods, and feelings (Zhang, 2013). Drawing on the psychology and social sciences literature, Zhang (2013) developed the Affective Response Model (ARM) to provide a foundation for technology-specific affective concepts.

This study aims to use a key element of ARM, known as the emotional episode. An emotional episode is a complex affective response, which comes from the interaction that a person has with a stimulus (Russell 2003). Zhang (2013) provided the theoretical underpinnings of the emotional episode, with a key description from Scherer (2005) who developed a set of characteristics for emotional episodes: 1) they are event-driven, in that a person triggers something to happen that leads to an emotional response after its significance is evaluated; 2) they are appraisal driven, in that the event and the subsequent consequences must be of some value to the person; 3) the relevance of the event is determined by a complex and rapidly occurring evaluation process; and 4) emotions are produced by the stimulus evaluation or appraisal checks which evaluate events in relation to the desires or goals of the person (Zhang 2013, Scherer 2005). Based on the above characteristics, and others provided by Russell (2003), Zhang (2013) developed the emotional episode in the technology context, illustrated in Figure 1, with constructs defined in Table 1.

$<$ Figure 1 here>

$<$ Table 1 here>

To illustrate an emotional episode, we can consider the following scenario. Imagine a person named Carolyn. She loves using technology and uses her phone to record her health-

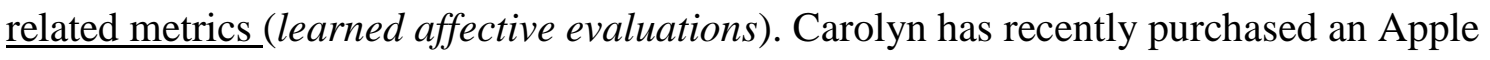


Watch to collect data about her swimming. During her first swim with the watch, she periodically checked on her progress, e.g. number of lengths, speed, distance, and calories burned. The real-time data gave her a lot of excitement and made her swim more enjoyable (emotions the perceiver has interacting with the stimulus). After her first swim, she thought the watch was very useful, as she could examine her performance, and was motivated to

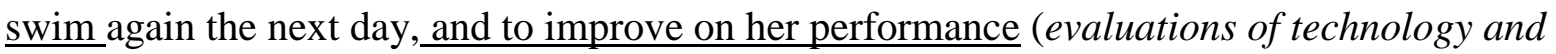
behaviors).

The focus of ARM is on the emotional relationship between a human user and a technical object. The theory does not explicitly relate emotions with affordances. Similar to the scenario provided above, we believe that it is affordances of technology that users feel emotional aspects towards and not the technology itself. Hence, we argue that an affordance perspective of emotional episodes is needed.

\subsection{Affordances}

The concept of affordance was first introduced by Gibson (1977), as possibilities of action that animals have within an environment, and may also be known as environmental affordances. Affordance focuses on the attribute of an object that permits or enables potential behaviors of animals or human beings (Michaels and Carello 1981). For example, a tree affords a cat to climb it. While the theory of affordance has been widely adopted in the technology literature, it is not as popular in the tourism literature. In the non-technological tourism literature, affordances such as beaches (Bærenholdt, Haldrup, and Urry 2004), forests (Rantala 2010), weather (Rantala, Valtonen, and Markuksela 2011), music (Waitt and Duffy 2010), and children's day programs on holiday (Agate, Agate, and Birchler 2015) have been discussed in terms of providing opportunities and creating an environment for certain activities, performances, and embodied experiences. Veijola and Valtonen (2007) argued that 
affordances are not the same for all bodies. For example, an airplane seat affords different levels of comfort for people of different body heights, weights, and genders.

Affordances of technology were first introduced by Norman (1999) about their design, development, and usage. When affordances are considered in the technology context, the original animal-environment relationship becomes a human-artifact relationship (Zheng and $\mathrm{Yu}$ 2016). Technological affordances consist of functional and social affordances. Functional affordances are defined as "the potential for behaviors associated with achieving an immediate concrete outcome and arising from the relation between an object (e.g., an IT artifact ) and a goal-oriented actor or actors" (Volkoff and Strong 2013, 823). Furthermore, technological systems also enable sociability amongst people independent of their physical location (Germann Molz and Paris 2015). These so-called social affordances emerged as the possibilities for social interactions between humans facilitated by technology (Zheng and $\mathrm{Yu}$ 2016). The relationships between three different types of affordances are illustrated in Figure 2. Functional affordances provide direct opportunities enabling users' certain behaviors; while social affordances are interpersonal relationships mediated by technologies. Both functional and social affordances are enabled or constrained by technologies directly or indirectly. Environmental affordances, on the other hand, focuses on the features of nontechnological material affordances that could potentially enable or constraint one's action.

$<$ Figure 2 here>

The affordance lens enables the researcher to consider the relationship between the capability of the technology, the context of its usage, and the possibilities of action (Majchrzak et al. 2013). Affordances are the possibilities of actions from using technology and are shaped by contexts such as their historical, institutional, and social environments (van Dijk et al. 2011, Zheng and Yu 2016). Furthermore, Faraj and Azad (2012) argue that the 
affordance unit of analysis should be examined as the entanglement between the technological capability, and the human action, which recognizes the relational aspect of affordances (Hutchby 2001).

A key way to explore technological affordances is through constructs such as affordance existence, affordance perception, affordance actualization, and affordance effect (Pozzi, Pigni, and Vitari 2014, Bernhard, Recker, and Burton-Jones 2013). Table 2 presents the description of each affordance construct and their supporting literature, including examples from technological research.

<Table 2 here>

From the existent literature of affordances and technology in tourism, three main themes emerged. The first theme is affordances from the perspective of the tourism service provider. Cabiddu, Carlo, and Piccoli (2014) explored customer engagement affordances for social media. They identified three affordances: persistent engagement (maintaining an ongoing conversation with customers), customized engagement (interacting with customers based on previous individual-level knowledge), and triggered engagement (instigating customer encounters from external customer-initiated events). Piccoli, Lui, and Grün (2017) explored affordances of service personalization for customer service in the hotel industry and found that technology enhances the efficiency of service personalization and the hotel guests' evaluation of service value.

The second theme is affordances from the perspective of the tourist. From a social affordances perspective, Germann Molz and Paris (2015) investigated the networked sociality of flashpackers (backpackers who travel with digital devices and more affluent budget). They identified four social affordances for flashpacking: virtual mooring in the statusphere (new social interactions through technology), following (how people interact with others in social 
media), collaborating (new possibilities for travelers to interact with other travelers), and (dis)connecting (unwanted disconnections due to power outage or lack of Internet access, and deliberate disconnections). Germann Molz (2013) introduced the concept of moral affordances during her study of couchsurfing.org. She argued that moral affordances help to explain how hosts and guests, who were previously strangers, create levels of trust through technology. Additionally, her study reveals how moral affordances enable the free sharing of resources, and engagement in caring relationships through social networking technologies.

The third theme is the use of affordance theory as a methodological tool. Larsen (2008) used affordance theory to develop a framework for researchers undertaking empirical studies of digital tourist photography. However, affordance theory was only a part of this framework, among other theoretical perspectives.

In our study, technological affordances can be understood as the use of technology that enables and/or constrains travelers' activities, such as looking up restaurants on TripAdvisor and maintaining contacts with friends and family during a holiday. Previous studies of affordances are mainly based on the existence of affordances (Volkoff and Strong 2013), without considering the effect of affordance changes or withdrawal. By investigating how the withdrawal of existing affordances might trigger changes in perceived, actualized and effected affordances, this new approach provides a critical understanding of affordance theory. Additionally, although there must be a human to actualize the affordance, the theory itself does not focus on cognitive elements of the human-artifact relationship. Based on previous studies on disconnected travel, we can conclude that the withdrawal of technological affordances will trigger various emotional responses (Pearce and Gretzel 2012, Paris et al. 2015); therefore, to gain a holistic understanding of how travelers experience emotions throughout the withdrawal and regain of technology we developed a conceptual framework linking two theoretical lenses. 


\subsection{Emotions and Affordances Conceptual Framework}

Travelers' disconnected emotions cannot be fully investigated without understanding them within situated conditions. We developed a conceptual framework (figure 3 ) linking the theories of emotional episodes and affordances to understand the holistic and complex emotional responses throughout the changes of affordances.

$<$ figure 3 here>

Our justifications for bringing these theories together are as follows. An emphasis on affordance brings in the contextual richness of the material and the environmental settings when understanding hybrid emotions. A key aspect of ARM is that an emotional episode arises from the interaction between a technological stimulus and a person. The technological stimulus has certain features and attributes. Although ARM does not discuss affordances specifically, it is features and attributes of technology which can be understood as affordances. For example, Google Maps has features such as cartographic displays, search and route displays, and location information which affords navigation. This is an affordance of Google Maps; however, there must be a person on the other side of the interaction to actualize this affordance, in other words, to do something with the technology.

This relationship between the technology and the human creates process-based or outcome-based evaluations or behavior towards a particular object (Zhang 2013). Faraj and Azad (2012) argue that the affordance unit of analysis is the entanglement between technological capability and human action. Therefore, we argue in our conceptual framework that during the human-technology interaction, the creation of an emotional episode is a response to a specific affordance. For example, based on our conceptual framework, one can say, "using Google Maps to navigate gives me a sense of relief when I am lost," which, applying our argument, can be understood in the following way: "using Google Maps 
(technological stimulus) to navigate (affordance) gives me (person) a sense of relief (affective response) when I am lost.” Applying this argument to our study, we can explore the affective responses when the technological stimulus, and its related affordances, are taken away. We can then explore how emotions and evaluations of technology change during the disconnection and reconnection process. 


\section{Methodology}

\subsection{Data Collection}

This study is underpinned by the interpretive paradigm using a diary method and semi-structured interviews. The majority of emotions and technology studies in tourism are quantitative (see Dickinger and Lalicic 2016, Neidhardt, Rümmele, and Werthner 2017, Lalicic and Weismayer 2016, Zakrisson and Zillinger 2012), with only a few examples of qualitative or conceptual studies. Kim and Fesenmaier (2015) argued that tourism research had dismissed the subjective and fluid aspects of these experiences. As a study investigating emotion-based digital free experience, the diary method was chosen to capture the richness of participants' live disconnected feelings and emotions from participants' point of view (Bolger, Davis, and Rafaeli 2003, Bartlett and Milligan 2015). In tourism studies, the diary method has been adopted to understand travel behavior and experiences (Axhausen et al. 2007, Vu et al. 2017) by monitoring factual experiences and changes of emotions during the trip (DeLongis, Hemphill, and Lehman 1992). Acting as a non-technological affordance, the diary provides opportunities for participants to record the instant emotional responses and express their feelings. Also, this study adopted semi-structured interviewed following the diary method to strengthen the interpretations (Hjalager and Nordin 2011, Markwell and Basche 1998), in particular, to further explore and understand participants' emotions beyond their own records.

Participants were recruited through a combination of self-selection and snowballing sampling techniques. A public Facebook post with the initial information (see appendix 1) was provided to invite potential participants to identify themselves and voluntarily participate in this research. Participants were free to arrange their own travel to different destinations. Further selection criteria were applied to ensure self-identified participants are frequent 
digital technology users and showing interest to take part in digital-free travel experiences. Most of the participants did not previously plan to participate in DFT, and voluntarily took part in this experience under our instructions. In the participant information, we operationalize our definitions of disconnection and technology: "We are interested to know about your experience and feelings when you travel without using any form of technology. We define technology as mobile, computer, laptop, tablet, Internet, social media, sat navigator, television, or radio/audio player".

The data collection was conducted in two stages. In the first stage, participants were instructed with guidelines to write diaries to record their instant emotions and detailed accounts before, during and after their disconnected experiences (see appendix 2). We asked participants to note down occasions where they had to finish the digital-free experience before their initial plan. Data analysis (see next section) began immediately to ensure that the data collected was adequate, and therefore data collection continued until saturation was reached when no new patterns from the data emerged (Fusch and Ness 2015). This stage was conducted from August 2016 to March 2017.

The richness of the diary data recorded several interesting narratives worth further investigations. To triangulate the data from participants' diaries, we conducted semistructured in-depth interviews (Myers and Newman 2007) to further investigate participants' reflections of their disconnected experiences in the second stage between April to October 2017. The semi-structured approach was chosen to ensure the data collected could help answer our research question, but also provide a detailed temporal narrative. The interview guidelines were customized based on participants' diaries in order to achieve deeper interpretations of their factual emotions. Due to the two-stage design in this study, participants' interviews provided further detailed explanations of their initial notes from their diaries. Also, twelve interviews were conducted for those participants who agreed to 
interviews only. Most of the interviews were conducted face-to-face; only one took place over the phone. Considering individual differences in terms of technology reliance, social and work commitments, as well as various types of holidays, we did not ask participants to disconnect for a certain length of time; they were free to reconnect again when they felt necessary. However, we asked participants to provide reasons why they decided to reconnect.

In total, 24 participants (14 male and 10 female) from 7 countries traveled to 17 countries and regions participated in this study (Table 3). Participants are mostly millennials excepts for two in the category of Generation X. All names are pseudonyms. Fifteen diaries were hand-written by participants and transcribed by them after their trips, 6 of them agreed for another round of interviews. Also, we conducted 12 interviews from those who agreed for interviews only. In total, we gathered 62 A4 pages of transcribed diaries; while interviews ranged from 45 minutes to an hour. Most participants disconnected for more than 24 hours with two exceptions, who provided reasons. Regardless of the length of disconnection, all participants reported a detailed account of their emotional changes. These trips cover a wide variety in terms of lengths and types of destinations, which provides useful insights into various influencing factors on emotions.

$<$ Table 3 here>

\subsection{Data Analysis}

All the data were transcribed and thematically analyzed through two cycles of abductive coding using NVivo software. The theory of affordance and emotional episode from the conceptual framework guided through the two stages of coding. By systematically combining deductive and inductive approaches (Dubois and Gadde 2002), our abductive approach combines provisional coding (deductive approach) and theoretical coding (inductive approach). Provisional coding (Miles, Huberman, and Saldaña 2014) was 
conducted in the first cycle of coding from a set of codes as a 'start list' (Table 4) agreed between three authors to categorize data into various stages of an emotional episode and associated affordance changes. In this cycle, although we applied a pre-defined scheme in the coding, we allowed for opportunities for new codes and themes to emerge outside the framework. Coding results were cross-checked between authors to ensure the consistency of the outcomes. Next, theoretical coding (Miles, Huberman, and Saldaña 2014) was adopted. This cycle of coding applied an inductive approach to condense prior codes into themes for a model generation (Corbin and Strauss 2008). In this stage, the authors continuously discussed and revised the codes to generate themes and final models. Some illustrative examples of our emerging concepts from the empirical data based on our conceptual framework are provided in Table 5.

$<$ Table 4 here>

$<$ Table 5 here>

After two cycles of abductive coding, six themes developed during the stages of predisconnection, disconnection, and re-connection (technological affordances changes), we organized these themes with the order of participants' journey. They are: established connectivity patterns and affective evaluation, pre-withdrawal symptoms, withdrawal symptoms, withdrawal acceptance/resistance, regain symptoms, and re-evaluate relationship with technology. 


\section{Findings and Discussion}

In this section, we explain the relationship between tourists' emotional changes based on the withdrawal and regain of technological affordances. Based on these contextual narratives, we then develop a theoretical model that links emotional reactions with affordance changes.

It is worth noting that not all participants experienced pre-withdrawal and withdrawal symptoms. Participants with strong motives to seek benefits from DFT often enjoyed the experience right away. Lauren and Noah both planned the digital detox and were looking forward to their holidays as they are usually highly connected. They are owners of start-ups and are on the phone almost 24/7 to be available for their clients and employees. During their holidays, they created a physical barrier and locked their phones away to be fully in the moment and enjoyed their time without constant distractions such as phone calls or emails: "It just became a thing that we just didn't need to check, so we just had our phones locked in our room in the safe and didn't even touch them for four or five days" (Lauren, interview).

On the other hand, some participants tried, but could not disconnect during their travels either because they did not feel secure and thought they would get lost, or because they had private commitments that did not allow them to be unavailable. Zhenpeng planned to disconnect for his trip in Macau, but found himself unable to engage in DFT: "thinking about it, without the phone, how do I take a bus? What to do if I take the wrong bus? How to find accommodation or the place I am planning to visit? Sometimes I need to find out when is the last bus or some other information. I am the kind of person who has a lack of sense of safety. Without my mobile phone it is very inconvenient. You cannot make last minute changes, and everything should be planned in advance" (interview). 
Six emotional episodes emerging from the thematic analysis were organized into three stages of technological affordance changes: connected, disconnected, and reconnected, in order to reflect the process of emotional responses and changes throughout the disconnecting and reconnecting event.

\subsection{Connected Stage (Pre-disconnect)}

\subsubsection{Established connectivity patterns and affective evaluation}

Most of our participants use various mobile apps and social media such as Google maps, TripAdvisor, Facebook and WhatsApp when they are on holiday. We found that the main reasons for using technology during their usual travels is because functional affordances provide 'convenience', 'safety', 'efficiency', but also for 'information acquisition' such as checking the weather (Stephan), Googling facts (Rory), or finding the best restaurant in town (Sally). Many interviewees mentioned the importance of efficiency: Larissa, who travelled to Kiev in Ukraine, stated that "travelling with technology is just so much easier and stressfree" (interview). The functional affordances of mobile phones and apps provided a sense of safety for our participants as getting lost can lead not only to frustration but also to anxiety especially when travelling alone in an environment with an unfamiliar culture, customs and language. Larissa, who could not speak Ukrainian, nor was she familiar with the Ukrainian culture, mentioned that she felt safer looking at her phone and pretended to be busy than asking for directions and therefore identifying herself as a tourist.

Checking information such as the weather, the best restaurant, or the fastest route was another factor that usually triggers travelers to use their phone during their travels. Rory, who went on a hiking trip to Able Tasman National, usually used her phone a lot on holiday: "as it is just so much more convenient" (interview). She noted that she would like to check her email and social media accounts, but also to look up information on Google every time they 
came across a question they could not answer. Rory emphasized the convenience of Google's information search affordance: "There were quite a few conversations that we had that we would have liked to check Google and then ah no we cannot Google it" (interview).

Many participants tried to avoid any micro-boredom in their daily lives and used any "unused time" to dive into their virtual worlds supported by digital-mediated social affordances. Confirming the statements of many participants, Zhenpeng, explained: "the other way to use technology is to kill time. Especially when I am commuting, I can read some news from Weibo or check WeChat" (interview).

Travelers use functional and social affordances in their everyday life and previous trips, such as information acquisition, navigation, and advice seeking. Given the benefits of ubiquitous connectivity in individuals' daily practices (Dery, Kolb, and MacCormick 2014), travelers develop relatively positive emotions towards technology. Not only because it is convenient, safe, and efficient, but also because it actively plays an essential role in cocreating travel experiences (Neuhofer, Buhalis, and Ladkin 2014).

\subsubsection{Pre-Withdrawal Symptoms}

Shortly before going offline, although still being able to leverage technological affordances, travelers' perceived affordances (Leonardi 2013) change as they are mentally preparing for the withdrawal of technologies. The change of perceived technological affordance created positive and/or negative emotions such as excitement and anxiety (Pearce and Gretzel 2012, Paris et al. 2015). Some participants were excited to disconnect from their commitments and the information overload they often experience in their daily lives. Rory, who is building her company with her fiancé, hoped that being disconnected from the Internet would let them enjoy each other's company and the environment with new people and different surroundings. 
Others had mixed feelings about the trip. Heike, who traveled with her partner Stephan from Austria to Cuba for the first time stated: "I was looking forward to it, but I was also a little bit uncertain and hoped that everything will work out. I also knew that I speak Spanish and people over there speak Spanish, so I thought we will figure it out. So, I was confident, but I also experienced a little bit of strain and hoped that everything will be fine" (interview). Being able to speak the local language gave our participants a lot of confidence as they could ask for directions and recommendations.

A few participants were very nervous and anxious about being disconnected for a couple of days as they were so used to travelling with technology and heavily relied on the associated technological functionalities. Using apps such as Google Maps and WhatsApp to orientate themselves or confirming meeting times and places became a habit for them. The idea of taking these functional and social affordances away from them created a lot of uncertainty and anxiety. Sally, who went on a trip to Queenstown, New Zealand expressed her concerns before the trip: "it made me feel anxious, even just talking about it now" (interview). Thomas, who was very nervous thinking about being disconnected, printed out two versions of maps, noted down all the details about how to get to the hotel from the airport and packed two travel guidebooks for his digital-free trip to Vienna.

Many participants had a lot of personal and professional commitments, which did not allow them to be disconnected and unavailable for a certain amount of time. Nico, interacted with his employees regularly through their collaboration platform "Slack" to ask and answer questions, shared information and managed their tasks. He noted that due to his responsibility and the critical time in the company, he almost could not switch off and hand over the responsibility to his employees: "to be honest, two days before the trip I was a little bit nervous about it, I was leaving them with a lot of responsibility of stuff in a particular area where they were not aware of everything, where they didn't understand everything. So, to a 
certain degree, two days before the trip I was like, do I really wanna do this? Is this really a good time?" (interview).

\subsection{Disconnected Stage}

\subsubsection{Withdrawal Symptoms}

In this stage, our participants experienced various emotions due to the withdrawal of technological affordances. Travelers actualized the affordance loss, which created an affordance effect (Groshek and Tandoc 2017), responding with either positive or negative withdrawal symptoms. During the first stage of disconnection, our participants showed different withdrawal symptoms. We found that while some people were at ease without having constant Internet access and not being in touch with their family and friends on social media, others were very frustrated, felt lonely and could not wait to switch on their phones.

\section{Anxiety, frustration and isolation}

Participants who were used to ubiquitous Internet access felt stranded and did not know how to find information at the early stage of disconnection. Susan who traveled with her fiancé to Tonga described their feelings of anxiety and isolation: "We were quite stressed when we arrived because we realized we did not even know how to get from the airport to the hotel, because we did not even know what we are doing the next day. So, there was a little bit of anxiety in the evening and the morning, because we had no idea what we are gonna do" (interview).

Many participants reported that they got very frustrated and anxious regarding navigation and information acquisition without the functional affordances. Sally, who is highly connected in her daily life, explained that she usually just followed the blue dot on Google Maps when she was travelling and had to walk to a specific location. She felt anxious in Queenstown when she tried to meet up with a friend but could neither contact her on 
WhatsApp to tell her that she might be late or lost nor use Google Maps to guide her way. Billy, who traveled to Switzerland and France, described how frustrating, difficult, and expensive it was to navigate and travel without technology. He and his friends could not look up the timetables on the Internet for the public transport, nor figure out the right transportation medium to find their way back to their accommodation: "Once we finished up at the bar, we tried to navigate our way back to the village we were staying. That was incredibly difficult without technology; no timetables, connection details or pricing could be found as all the transport offices/counters were closed past 8 pm. Without technology to guide us home, we missed a bus and took the wrong tram and ended up having to spend 35 CHF each on a cab ride home" (diary).

Many participants also reported frustrations about being unable to acquire information instantly. Tech-savvy user James was very frustrated when travelling digitally-free in Vienna: "Now I am looking at the city map the hotel gave us. I can see a small river and then a larger one, but it's cut off the map. I want to check what it is and where it goes but I have no Internet access. The river says 'Donau' and 'Neve Donau'. I'll check when I get access again. I feel frustrated when I cannot find the information I want" (diary).

Social affordances have created expectations from family, friends and work colleagues towards participants being available and responsive not just in their daily life but also during their holidays. Many participants worried their friends and families would get worried if they did not respond promptly. Frank, who travelled to Massachusetts, USA said: "I hadn't mentioned to anyone outside of my travel friends that I was going without technology that day so I was worried that they might have been wondering why I had disappeared and been non-responsive" (diary). Others were worried that their family and friends could not contact them, in case of an emergency. Especially travelling in foreign countries, many participants mentioned that their smartphone gave them a sense of safety as 
they can make use of the social affordances enabled by technologies and call their contacts in case something happened to them. Youngqi who travelled from China to Neuschwanstein in Germany, which is a small village in the mountains, stated her concerns: "the issue is when you are disconnected, there is a chance that I might be in danger or some accident, and my families cannot reach me, I have this concern. It creates this kind of anxiety" (interview).

Some participants felt isolated and lonely with the withdrawal of social affordances, not being able to chat with their friends or family members through Facebook or WhatsApp: "the anxiety and stress-inducing feelings came from feeling isolated-at least, isolated from those people who weren't with me on the trip, in particular, my significant other" (Frank, diary). James woke up in Vienna on the first day of his DFT experience feeling lonely without the company of his phone: "usually before I get out of bed, I will check my emails, Facebook and the news. But I just lay there staring at the wall. I went to breakfast and saw others using their phones and I felt envious of them. When I eat alone, I would usually look at Facebook or 9Gag while eating. I felt very isolated and alone. So, I tried to listen to other people's conversations, but the majority were not in English" (diary).

We also found that many people got bored not using their phones, as it is also their personal entertainer during downtimes, for example, before going to bed or waiting for the bus. Billy described that he felt the urge to use his phone the most as soon as he was lying in bed. During this time, he and a lot of other participants used social affordances, e.g. scrolling through Facebook or texting friends and family members in the evenings: "the real desire came before bed where I, once again, aimlessly scroll through Facebook, watch stupid YouTube videos and/or listen to music" (Billy, diary). James, who usually carried his phone all the time and everywhere "felt so weird" that he did not have his phone on him that he put a notebook in his right pocket, where usually his phone sits. 
In addition to confirming emotions of distress and anxiety (O'Regan 2008), the findings provide a more complex picture of withdrawal emotions. These withdrawal symptoms are highly related to travelers' 'learned affective evaluations' (Zhang 2013) before the disconnecting event. Technologies today provide ubiquitous Internet access as a functional affordance (Grgecic, Holten, and Rosenkranz 2015) and networked sociality as a social affordance (McGrath, Bresciani, and Eppler 2016). When the disconnecting event occurs, travelers evaluated the benefits and loss relating to the withdrawal of the functional and social affordances that technology previously enabled, and responded with positive or negative emotions. These withdrawal symptoms can be understood as the outcome of losing affordances.

\section{Liberation, Appreciation and Social re-engagement}

Being cut off from the constant information flow felt like a liberation for many of our participants, and they realized how much information they digest in their daily life. For example, Sean, who travelled to Tonga with his fiancé, emphasized the enjoyment that he could take a break from all the everyday information: "I liked it, I think it was more relaxing. I thought it is like unplugging from everyday life; it was disconnecting from all the bullshit like keeping track of the news and stuff like that. Kind of really being present" (interview).

Due to the loss of technological affordances, travelers started to perceive and actualize other environmental affordances and engaged in more social interactions at the destination that they previously ignored. This shift especially had stronger effects on those tech-dependent travelers, who were preoccupied with technological affordances, and started to appreciate or hesitated to leverage the changes in affordances. In this process, these new or regained environmental affordances usually provided a positive affordance effect (Bernhard, Recker, and Burton-Jones 2013). Many participants pointed out that they were much more attentive and focused on their surroundings. They were present and immersed in the physical 
world, rather than getting distracted by incoming messages, notifications or alerts from their mobile apps. Like other statements from our participants, Thomas described the feeling of losing 'psychological weight' when he disconnected in Ely, England: "without holding the phone on my hand or in my pocket, I feel much 'lighter'. It is a psychological feeling. I feel I am more open to what is going on nearby instead of being into things on my social media" (diary).

The withdrawal of technological affordances provided more opportunities for social interactions. Most participants were quite hesitant at the beginning as they were not used to asking other people for directions. They usually just opened Google Maps, typed in the address of their destination and then followed the instructions. Sally described that initially, she hesitated to ask the locals for the directions; however, she enjoyed it after a while and was surprised that most of the locals were kind and helpful: "it ended up being fun because just randomly talking to people. You just don't do that anymore so that was interesting" (diary).

By talking to other travelers, and especially locals, many participants reported that they were given excellent advice and learned more about sights, places and beaches that were not on any tourism websites or guidebooks, but were beautiful and a highlight of their trips. Lisa, who visited Taipei with her partner for three days, reported that they were looking for a famous temple. Accidentally, they found another much smaller but mind-blowing temple on this alley. Two older men were sitting at the entrance, and one of them offered Lisa and her boyfriends some tea, so they sat down together, and the man who invited them started talking about the history of the temple and the district. Afterwards, his friend gave them two talismans and wished them good luck for their travels. Getting lost due to the lack of technological affordances offers excellent opportunities to explore new places, get in contact with locals, learn about their history, and offers new experiences. 
Our participants reported that they not only engaged more with other travelers and locals during their disconnected travels, but that they also spent more time with their travel companions. As Susan and her partner were completely disconnected, they were not distracted by their phones, especially social media or online games: "I only enjoyed it because Sean tends to be on his phone and the internet quite a bit. So, we were less occupied with our phones. Just more talking, more reading” (interview).

\subsubsection{Withdrawal Acceptance and Resistance}

After experiencing different withdrawal symptoms, some travelers developed positive effects towards their travel experience (acceptance). On the other hand, it was difficult for some to engage with these new environmental affordances. Going through the same affordances change, these travelers developed a negative attitude, and could not wait to reconnect (resistance).

We found that some participants embraced and enjoyed the disconnected experience after going through various levels of initial struggles: Heike, who visited Cuba, began to love not being reliant on technological affordances after suffering from the initial withdrawal symptoms, and reported that she did not even want to re-connect, even given the option to use the Wi-Fi in public places in Cuba. She did not want her daily life to intrude her holidays, as she enjoyed being far away from everything and she wanted to maintain that liberating feeling: "Stephan bought a card so that we can connect at Wi-Fi hotspots. And then we thought we would connect now and then, but then we just did not do it as it felt far too tiring" (interview).

For some participants, it took a little bit longer to accept the disconnected experience. These participants usually always travel with technology and heavily rely on technological affordances in their private and professional lives. Thomas described this transition process: 
"we are now on our way to Schoenbrunn Palace. Yesterday was the first full day we travelled without technology. Comparing with the panic and anxiety in the first day of arrival, the second day, I feel I am using materials we have in hand much better. With map in hand and guidebook, it is easy to get around"(diary). Frank emphasised that he was proud of being able to travel disconnected, although he is usually highly connected and reliant on technology. "I feel quite good that I made it this far without technology. I feel quite liberated" (diary).

On the other hand, Larissa who visited Kiev, Ukraine, experienced the affordances changes but could not remain disconnected due to the strong reliance on technological affordances. Initially, she tried to disconnect, however, it did not seem to work primarily because she could not speak the language, nor could she read the street signs as they were in Cyrillic letters. Larissa was on her own and had concerns about her safety as Ukraine had experienced a significant political revolution and had turmoil all over the country, especially in Kiev. She explained: "Kiev is extreme and difficult, especially the language, because the letters are different, and Russian and Ukrainian are languages I do not understand at all. That was the first reason, because navigating with Cyrillic letters is absolutely overwhelming. Now and then something is written in Latin letters; however, if you do not know that place at all, it is challenging to orientate yourself, especially in the beginning. So, the reasons [for being unable to disconnect] were the language, the writing, and that I was on my own. I was really scared about that; I thought I do not want to get lost" (interview).

\subsection{Reconnected Stage}

During the reconnection phase, our participants regained their technological affordances, which were the same as in the pre-disconnecting stage. However, their perceptions and actualizations of technological affordance had changed. 


\subsubsection{Regain symptoms}

Many participants reported that they were upset and overwhelmed as soon as they got hit by all the incoming messages and notifications that they received over the days they were disconnected. Nico, who disconnected on a hiking trip on the South Island of New Zealand, saw all the messages and could not even be bothered to read them as it seemed so overwhelming and distracting. He decided to switch his phone off again until he arrived at the airport and had some time to kill. Others realized how addicted they were to their phone and that "chasing likes on social media" seemed to be so superficial after being disconnected for a while. James, who traveled to Vienna in Austria and reconnected on his birthday, explained: "It was rather disappointing turning my phone back on. Seeing the Facebook likes and messages I had (not the happy birthday ones, but the ones I had received while disconnected), I felt how superficial they were. Not important stuff. I started to think why am I so addicted to counting my likes and reading comments that don't really have a huge impact on my life? Technology, especially Facebook, has become my life" (diary).

Other participants were happy about the regain of technological affordances, although most of them were not starving for connectivity. Sean, who enjoyed the digital-free experience, was looking forward to reconnecting his phone again as soon as he came home from his Tonga trip: "when we landed, I was looking forward to getting it to work" (interview). The participants appreciated the time being disconnected from work and private commitments, but they were also glad to be able to chat to their friends and family members again, to share their experiences and send photos around enabled by social affordances. Sally noted that just the feeling of knowing what is going on and to be in the loop again, made her relieved: "Even if I didn't answer anybody or answer an email or reply to anything on Facebook, I know what's going on now, so that was a relief already" (interview). Others were happy to get on top of their social and work-related commitments again enabled by the 
regained social and functional affordances and did "maintenance tasks" such as responding to emails and social media messages. Dough talked about this reconnecting moment: "I was at the airport about to fly home and then I spent probably 40 minutes straight doing maintenance tasks... it was mostly responding to work emails...It felt good to catch up" (interview). He realized that he got an urgent email on Friday, but he did not respond to it until Monday. Because of this, he could have missed a great opportunity as they had a deadline; however, he still managed to get the work done. He was not too upset about that incident and claimed that it would not have been the end of the world if he would have missed the opportunity.

\subsubsection{Re-Evaluate Relationship with Technology}

After the disconnect/reconnect experience, travelers had the opportunity to evaluate their relationship with technologies (Zhang 2013) and other environmental affordances. Participants reported a higher engagement with physical environments and partaking in conversations with locals, as they actualized and engaged with these usually unperceived environmental affordances and social interactions when they were disconnected. Having enjoyed the engagement with locals and physical surroundings during disconnection, some participants decided to have another digital detox (Paris et al. 2015) in the future.

By understanding the shift of travelers' affordance perception and actualization in these three phases of technological affordance changes (connection, disconnection, reconnection), this study provides comprehensive insights into the intertwining relationship between technological affordances and environmental affordances. In this study, we found that before disconnection, although both technological and non-technological affordances provided possibilities of actions (Gibson 1977), most tech-dependent travelers largely overlooked environmental affordances and other potential social interactions, as technological affordances predominantly occupied them. Potentially leading to value co- 
destruction on holiday, where using technology might have an adverse affect (Neuhofer 2016). Throughout the disconnecting experience, when technological affordances were withdrawn, travelers discovered and learned to appreciate environmental affordances and new social interactions that they neglected before, in other words, those obscured affordances converted into perceived, alternative opportunities. Also, the relationship between preoccupied perceived affordances and previously neglected existing affordances has been reexamined by travelers when reconnecting. The fluidity between existing and potential affordances, as well as technological and environmental affordances, contributes to the affordance literature through the lens of liquid modernity (Bauman 2000).

\subsection{Influencing Factors}

Various factors affected how travelers perceived the DFT experience. These identified influencing factors are the type of destination, travel companions, social and professional commitments, reliance level of technology in their day to day life, and motivation for disconnecting. Firstly, participants suffered withdrawal symptoms of anxieties and frustrations more in urban destinations due to the need for navigation, instant information access, and digital word-of-mouth recommendation seeking. Participants in rural and natural destinations, on the other hand, tended to have withdrawal symptoms related to being unable to report safety or kill time. We also found that participants travelling as a couple, or in a group, tended to be more confident to disconnect than solo travelers. Participants reported suffering less or even had no negative withdrawal symptoms when travelling with companions who are connected; while solo travelers tended to feel somewhat vulnerable without technological assistance to buffer cultural shock.

On a personal level, withdrawal symptoms tended to be stronger for travelers who participated in DFT with many social and professional commitments. They are also more likely to have negative disconnected experiences. Also, the level of technological dependence 
and willingness to disconnect also influenced the emotional curve throughout the disconnecting and reconnecting process. These influencing factors affected the level of participants' withdrawal emotions throughout the connect-disconnect-reconnect process, which is reflected in our proposed model (section 4.5). Every individual has his/her emotional trail with certain levels of withdrawal responses, such as symptoms, acceptance and rejection throughout the affordance change.

\subsection{Disconnected Emotions Model (DEM)}

In addition to developing ARM (Zhang 2013) further in a connect/disconnect/reconnect context, and synthesizing the intertwining relationships between affordances (technological, social, and environmental) and emotions, we develop the Disconnected Emotions Model (DEM) to provide comprehensive insights into the relationship between affordance changes and disconnected emotional variations. As illustrated in DEM (figure 4), human and IT artifacts are placed at opposite ends of the spectrum. Emotions are more closely related to the human side, while technological affordances are more related to the IT artifacts side. Both emotional changes and affordance changes have reverse focus and perspective towards the same disconnect/connect events. Perceived, actualized and effect affordances link the theory of affordance and the theory of emotional episode with human and IT artifacts in the same framework. The embodied and situated 'doing' of travelers is the key to link affordances and emotions in DEM. As key constructs of affordances (Bernhard, Recker, and Burton-Jones 2013, Pozzi, Pigni, and Vitari 2014), perceived, actualized and effect affordances indicate the process of emotion creation by utilizing technological artifacts. On the one hand, these three types of affordances emphasize the fundamental role of IT artifacts that provide possibilities for potential behaviors (Michaels and Carello 1981); on the other, they emphasize how human beings' emotions change when they perceive and actualize these changes of technological affordance. 
By considering both technological affordances and environmental affordances, as well as the change of perceptions towards various affordances, DEM not only provides a new understanding of users' emotion changes when using or disconnecting from technologies but also proposes the fluidity of various affordances that are perceived by travelers in a disconnecting event. Furthermore, DEM also contributes to the affordance literature by effectively arguing that emotions are outcomes of perceived, actualized and effected affordances; therefore, it strengthens the understanding of affordance from the users' end.

<Figure 4 here> 


\section{Conclusion}

This study contributes to tourism literature by exploring complex emotions in the holistic disconnected process. We answered our research question by providing detailed accounts of how stages of technology withdrawal and regain trigger participants' different emotional responses. In the findings, we also explained how cognitive and environmental factors influence the digital-disconnected experience. We developed DEM, which links affordances and emotions through empirical understandings of self-initiated DFT experiences. As the majority of emotions and technology research was based on quantitative analysis, DEM provides in-depth qualitative insights by shifting away from just the humancentric understanding of emotions to a more in-depth focus on materiality in tourism studies. DEM provides a new perspective of understanding emotions by highlighting the effect of the significant and relational role of material affordance changes. By answering the research question, this paper is the first to theoretically link affordances with emotions, and provide a comprehensive understanding of the hybrid and dynamic emotional journey that digital-free travelers are experiencing.

Practically, this study provides valuable implications for tour operators and destination marketing organizations to gain better understandings of travelers' emotions when developing 'off-the-grid' packages or tech-savvy tour products. Understanding what triggers consumers' negative and positive emotions can help service providers to improve products and marketing strategies.

Some limitations were identified in this study. Firstly, the sample of participants came from the researchers' personal contacts, which, to some extent, limits the reach participants' backgrounds and destinations. Secondly, with the focus of synthesizing emotions throughout the whole process of affordance changes, when recruiting participants, we did not 
differentiate types of holidays, travel companions, and lengths of disconnection in this study. Based on various influencing factors identified from the findings, quantitative approaches should be applied in future research to test their relationships and significance. Thirdly, as emotions were based on self-reports from participants, there is a lack of close observations of these emotions. A mobile ethnographic approach can be applied in future research to gain a thick description of their experiences. Future studies can further explore and apply DEM beyond the context of the disconnected holiday to provide a broader understanding of the togetherness of materiality (technologies) and cognitive responses connected by embodied practice. This new angle will provide a critical account in a widely researched area such as technology use by investigating emotional response due to the design and the context of specific types of technology or application. Furthermore, based on various emotions discussed in this article, more studies should be undertaken to investigate the complex influences such as professional and personal commitments, as well as long-term impacts on wellbeing. 


\section{References}

Agate, J. R., S. T. Agate, and K. Birchler. 2015. "A vacation within a vacation: Children's day programs and parental satisfaction." Tourism, Culture and Communication 15 (1):21-32.

Axhausen, Kay W, M Löchl, R Schlich, T Buhl, and P Widmer. 2007. "Fatigue in longduration travel diaries." Transportation 34 (2):143-160.

Ayeh, Julian K. 2018. "Distracted gaze: Problematic use of mobile technologies in vacation contexts." Tourism Management Perspectives 26:31-38.

Bærenholdt, Jørgen Ole, Michael Haldrup, and John Urry. 2004. Performing tourist places. Aldershot: Routledge.

Bartlett, Ruth, and Christine Milligan. 2015. What is Diary Method?: Bloomsbury Publishing.

Bauman, Zygmunt. 2000. Liquid modernity. Cambridge: Polity Press.

Beaudry, Anne, and Alain Pinsonneault. 2010. "The other side of acceptance: studying the direct and indirect effects of emotions on information technology use." MIS quarterly 34 (4):689-710.

Bernhard, Eike, Jan C Recker, and Andrew Burton-Jones. 2013. "Understanding the actualization of affordances: A study in the process modeling context." Thirty Fourth International Conference on Information Systems, Milan.

Bolger, Niall, Angelina Davis, and Eshkol Rafaeli. 2003. "Diary methods: Capturing life as it is lived." Annual review of psychology 54 (1):579-616.

Buhalis, Dimitrios. 2003. eTourism: Information technology for strategic tourism management: Pearson Education.

Cabiddu, F., M. D. Carlo, and G. Piccoli. 2014. "Social media affordances: Enabling customer engagement." Annals of Tourism Research 48:175-192. 
Chemero, Anthony. 2003. "An outline of a theory of affordances." Ecological psychology 15 (2):181-195.

Cohen, Scott A, and Erik Cohen. 2019. "New directions in the sociology of tourism." Current Issues in Tourism 22 (2):153-172.

Cohen, Scott A., Girish Prayag, and Miguel Moital. 2014. "Consumer behaviour in tourism: Concepts, influences and opportunities." Current Issues in Tourism 17 (10):872-909. Corbin, J., and A. Strauss. 2008. Basics of qualitative research: Techniques and procedures for developing grounded theory. 3rd ed. Thousand Oaks, CA: Sage.

DeLongis, Anita, Kenneth J Hemphill, and Darrin R Lehman. 1992. "A structured diary methodology for the study of daily events." Methodological issues in applied social psychology 2:83-109.

Dery, Kristine, Darl Kolb, and Judith MacCormick. 2014. "Working with connective flow: how smartphone use is evolving in practice." European Journal of Information Systems 23 (5):558-570.

Dickinger, Astrid, and Lidija Lalicic. 2016. "An analysis of destination brand personality and emotions: a comparison study." Information Technology \& Tourism 15 (4):317-340.

Dickinson, Janet E, Julia F Hibbert, and Viachaslau Filimonau. 2016. "Mobile technology and the tourist experience: (Dis)connection at the campsite." Tourism Management 57:193-201.

Dubois, Anna, and Lars-Erik Gadde. 2002. "Systematic combining: an abductive approach to case research." Journal of business research 55 (7):553-560.

Faraj, Samer, and Bijan Azad. 2012. "The materiality of technology: An affordance perspective." In Materiality and organizing: Social interaction in a technological world, edited by P. M. Leonardi, B. Nardi and J. Kallinikos, 237-258. Oxford: Oxford University Press. 
Fusch, Patricia I, and Lawrence R Ness. 2015. "Are we there yet? Data saturation in qualitative research." The qualitative report 20 (9):1408-1416.

Germann Molz, Jennie. 2013. "Social networking technologies and the moral economy of alternative tourism: The case of couchsurfing. org." Annals of tourism research 43:210-230.

Germann Molz, Jennie, and Cody Morris Paris. 2015. "The Social Affordances of Flashpacking: Exploring the Mobility Nexus of Travel and Communication." Mobilities 10 (2):173-192.

Gibson, J. J. 1977. "The theory of affordances." In Perceiving, acting and knowing, edited by R. E. Shaw and J. Bransford. Hillsdale: Lawrence Erlbaum Associates.

Grgecic, Daniel, Roland Holten, and Christoph Rosenkranz. 2015. "The Impact of functional affordances and symbolic expressions on the formation of beliefs." Journal of the Association for Information Systems 16 (7):580-607.

Groshek, J., and E. Tandoc. 2017. "The affordance effect: Gatekeeping and (non)reciprocal journalism on Twitter." Computers in Human Behavior 66:201-210.

Haldrup, Michael, and Jonas Larsen. 2006. "Material cultures of tourism." Leisure studies 25 (3):275-289.

Hartson, Rex. 2003. "Cognitive, physical, sensory, and functional affordances in interaction design." Behaviour \& Information Technology 22 (5):315-338.

Hjalager, Anne-Mette, and Sara Nordin. 2011. "User-driven innovation in tourism-A review of methodologies." Journal of Quality Assurance in Hospitality \& Tourism 12 (4):289-315.

Huang, Yu-Chih, Sheila J. Backman, Kenneth F. Backman, and DeWayne Moore. 2013. "Exploring user acceptance of 3D virtual worlds in travel and tourism marketing." Tourism Management 36:490-501. 
Hutchby, Ian. 2001. "Technologies, texts and affordances." Sociology 35 (2):441-456.

Karla, Straker, and Wrigley Cara. 2016. "Translating emotional insights into digital channel designs: Opportunities to enhance the airport experience." Journal of Hospitality and Tourism Technology 7 (2):135-157.

Kim, Jeongmi, and Daniel R. Fesenmaier. 2015. "Measuring Emotions in Real Time: Implications for Tourism Experience Design." Journal of Travel Research 54 (4):419-429.

Lalicic, Lidija, and Christian Weismayer. 2016. "The passionate use of mobiles phones among tourists." Information Technology \& Tourism 16 (2):153-173.

Larsen, Jonas. 2008. "Practices and flows of digital photography: An ethnographic framework." Mobilities 3 (1):141-160.

Lee, Seonjeong Ally, Miyoung Jeong, and Myunghee Mindy Jeon. 2016. "Effects of experiential stimuli on customers' responses: An example of bed and breakfast websites." Journal of Hospitality and Tourism Technology 7 (4):390-404.

Lee, Seonjeong, and Miyoung Jeong. 2012. "Effects of e-servicescape on consumers' flow experiences." Journal of Hospitality and Tourism Technology 3 (1):47-59.

Leonardi, Paul M. 2013. "When Does Technology Use Enable Network Change in Organizations? A Comparative Study of Feature Use and Shared Affordances." MIS Quarterly 37 (3):749-775.

Li, Jing, Philip L. Pearce, and David Low. 2018. "Media representation of digital-free tourism: A critical discourse analysis." Tourism Management 69:317-329.

Majchrzak, Ann, Samer Faraj, Gerald C Kane, and Bijan Azad. 2013. "The contradictory influence of social media affordances on online communal knowledge sharing." Journal of Computer-Mediated Communication 19 (1):38-55. 
Majchrzak, Ann, and M Lynne Markus. 2012. Technology affordances and constraints in Management Information Systems (MIS). In Encyclopedia of management theory. Thosand Oaks: Sage Publications.

Markus, M Lynne, and Mark S Silver. 2008. "A foundation for the study of IT effects: A new look at DeSanctis and Poole's concepts of structural features and spirit." Journal of the Association for Information systems 9 (10/11):609-632.

Markwell, Kevin, and Christopher Basche. 1998. "Using personal diaries to collect data." Annals of Tourism Research 25 (1):228-231.

McGrath, L., S. Bresciani, and M. J. Eppler. 2016. "We walk the line: Icons provisional appearances on virtual whiteboards trigger elaborative dialogue and creativity." Computers in Human Behavior 63:717-726.

Michaels, C. F., and C. Carello. 1981. Direct perception. Englewood Cliffs, NJ: PrenticeHall.

Miles, M. B., A. M. Huberman, and J Saldaña. 2014. Qualitative Data Analysis: A Methods Sourcebook. 3rd ed. Thousand Oaks, CA: Sage.

Myers, M. D, and M. Newman. 2007. "The Qualitative Interview in Is Research: Examining the Craft." Information and Organization 17 (1):2-26.

Navío-Marco, Julio, Luis Manuel Ruiz-Gómez, and Claudia Sevilla-Sevilla. 2018. "Progress in information technology and tourism management: 30 years on and 20 years after the internet - Revisiting Buhalis \& Law's landmark study about eTourism." Tourism Management 69:460-470.

Neidhardt, Julia, Nataliia Rümmele, and Hannes Werthner. 2017. "Predicting happiness: user interactions and sentiment analysis in an online travel forum." Information Technology \& Tourism 17 (1):101-119. 
Neuhofer, Barbara. 2016. "Value Co-creation and Co-destruction in Connected Tourist Experiences." In Information and Communication Technologies in Tourism 2016, edited by Alessandro Inversini and Roland Schegg, 779-792. Cham: Springer International Publishing.

Neuhofer, Barbara, Dimitrios Buhalis, and Adele Ladkin. 2014. "A typology of technologyenhanced tourism experiences." International Journal of Tourism Research 16 (4):340-350.

Neuhofer, Barbara, Dimitrios Buhalis, and Adele Ladkin. 2015. "Technology as a Catalyst of Change: Enablers and Barriers of the Tourist Experience and Their Consequences." In Information and Communication Technologies in Tourism 2015, edited by Iis Tussyadiah and Alessandro Inversini, 789-802. Cham: Springer International Publishing.

Neuhofer, Barbara, and Adele Ladkin. 2017. "(Dis)Connectivity in the Travel Context: Setting an Agenda for Research." In Information and Communication Technologies in Tourism 2017, edited by R. Schegg and B. Stangl, 347-359. Rome, Italy: Springer. Norman, Donald A. 1999. "Affordance, conventions, and design." Interactions 6 (3):38-43. O’Regan, Michael. 2008. "Hypermobility in backpacker lifestyles: The emergence of the internet café." In Tourism and mobilities: Local-global connections, edited by P. Burns and M. Novelli, 109-132. Walingford: CABI.

Paris, Cody Morris, Edward Alexander Berger, Simon Rubin, and Mallory Casson. 2015. "Disconnected and unplugged: experiences of technology induced anxieties and tensions while traveling." In Information and Communication Technologies in Tourism 2015, edited by I. Tussyadiah and A. Inversini, 803-816. London: Springer. 
Pearce, Philip L, and Ulrike Gretzel. 2012. "Tourism in technology dead zones:

Documenting experiential dimensions." International Journal of Tourism Sciences 12 (2):1-20.

Piccoli, G., T. W. Lui, and B. Grün. 2017. "The impact of IT-enabled customer service systems on service personalization, customer service perceptions, and hotel performance." Tourism Management 59:349-362.

Pozzi, Giulia, Federico Pigni, and Claudio Vitari. 2014. "Affordance theory in the IS discipline: A review and synthesis of the literature." 20th Americas Conference on Information Systems (AMCIS).

Rantala, Outi. 2010. "Tourist practices in the forest." Annals of Tourism Research 37 (1):249-264.

Rantala, Outi, Anu Valtonen, and Vesa Markuksela. 2011. "Materializing tourist weather: ethnography on weather-wise wilderness guiding practices." Journal of Material Culture 16 (3):285-300.

Robinson, Peter. 2014. "Emediating the tourist gaze: memory, emotion and choreography of the digital photograph." Information Technology \& Tourism 14 (3):177-196.

Rosenberg, Hananel. 2019. "The "flashpacker" and the "unplugger": Cell phone (dis)connection and the backpacking experience." 7 (1):111-130.

Russell, James A. 2003. "Core affect and the psychological construction of emotion." Psychological review 110 (1):145-172.

Scherer, Klaus R. 2005. ""What are emotions?" And how can they be measured?" Social science information $44(4): 695-729$.

Stein, Mari-Klara, Sue Newell, Erica L Wagner, and Robert D Galliers. 2015. "Coping with Information Technology: Mixed Emotions, Vacillation, and Nonconforming Use Patterns." Mis Quarterly 39 (2):367-392. 
Stoffregen, Thomas A. 2003. "Affordances as properties of the animal-environment system." Ecological psychology 15 (2):115-134.

Stoffregen, Thomas A, Kathleen M Gorday, Yang-Yi Sheng, and Steven B Flynn. 1999. "Perceiving affordances for another person's actions." Journal of Experimental Psychology: Human Perception and Performance 25 (1):120-136.

Strong, Diane M, Sharon A Johnson, Bengisu Tulu, John Trudel, Olga Volkoff, Lori R Pelletier, Isa Bar-On, and Lawrence Garber. 2014. "A Theory of Organization-EHR Affordance Actualization." Journal of the Association for Information Systems 15 (2):53-85.

Tanti, Adrian, and Dimitrios Buhalis. 2016. "Connectivity and the Consequences of Being (Dis)connected." In Information and Communication Technologies in Tourism 2016, edited by Alessandro Inversini and Roland Schegg, 31-44. Cham: Springer International Publishing.

Tim, Y., S. L. Pan, S. Bahri, and A. Fauzi. 2017. "Digitally enabled affordances for community-driven environmental movement in rural Malaysia." Information Systems Journal Article in Press.

Tribe, John, and Muchazondida Mkono. 2017. "Not such smart tourism? The concept of elienation." Annals of Tourism Research 66:105-115.

Turvey, M. T. 1992. "Affordances and Prospective Control: An Outline of the Ontology." Ecological Psychology 4 (3):173-187.

UK Gadget Habit Report. 2017. "The UK Gadget Habit Report: Uncovering our passion for everyday tech." Electric Tobacconist Accessed 28 Nov 2017. https://www.electrictobacconist.co.uk/uk-gadget-usage-report-2017-i276. 
van Dijk, Stephan, Hans Berends, Mariann Jelinek, A Georges L Romme, and Mathieu Weggeman. 2011. "Micro-institutional affordances and strategies of radical innovation." Organization Studies 32 (11):1485-1513.

Veijola, S. , and A. Valtonen. 2007. "The Body in Tourism Industry." In Tourism \& Gender: Embodiment, Sensuality and Experience, edited by A. Pritchard, N. Morgan, I. Atelejevic and C. Harris, 13-31. Oxfordshire: CABI Publishing.

Volkoff, Olga, and Diane M Strong. 2013. "Critical Realism and Affordances: Theorizing ITassociated Organizational Change Processes." Mis Quarterly 37 (3):819-834.

Vu, Huy Quan, Gang Li, Rob Law, and Yanchun Zhang. 2017. "Tourist Activity Analysis by Leveraging Mobile Social Media Data." Journal of Travel Research 57 (7):883-898.

Waitt, Gordon, and Michelle Duffy. 2010. "Listening and tourism studies." Annals of Tourism Research 37 (2):457-477.

Zakrisson, Ingrid, and Malin Zillinger. 2012. "Emotions in motion: tourist experiences in time and space." Current Issues in Tourism 15 (6):505-523.

Zhang, Ping. 2013. "The affective response model: A theoretical framework of affective concepts and their relationships in the ICT context." MIS quarterly 37 (1):247-274.

Zheng, Yingqin, and Ai Yu. 2016. "Affordances of social media in collective action: the case of Free Lunch for Children in China." Information Systems Journal 26 (3):289-313. 


\section{Figure 1}

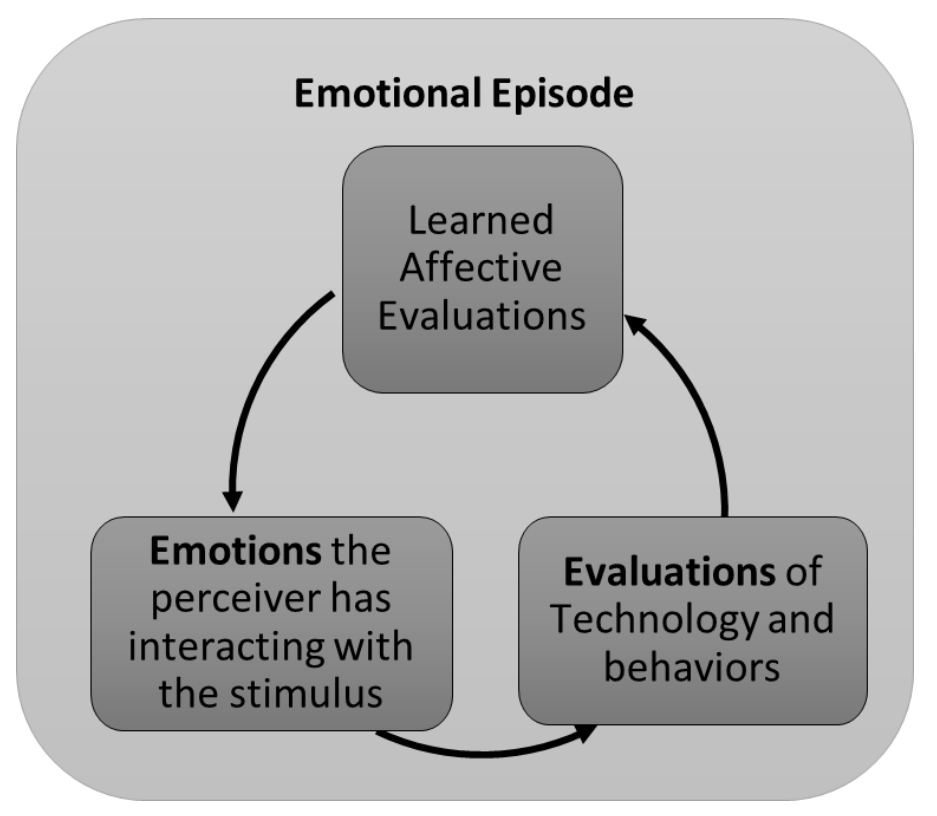

Figure 1: Emotional Episode (Zhang 2013) 


\section{Figure 2}

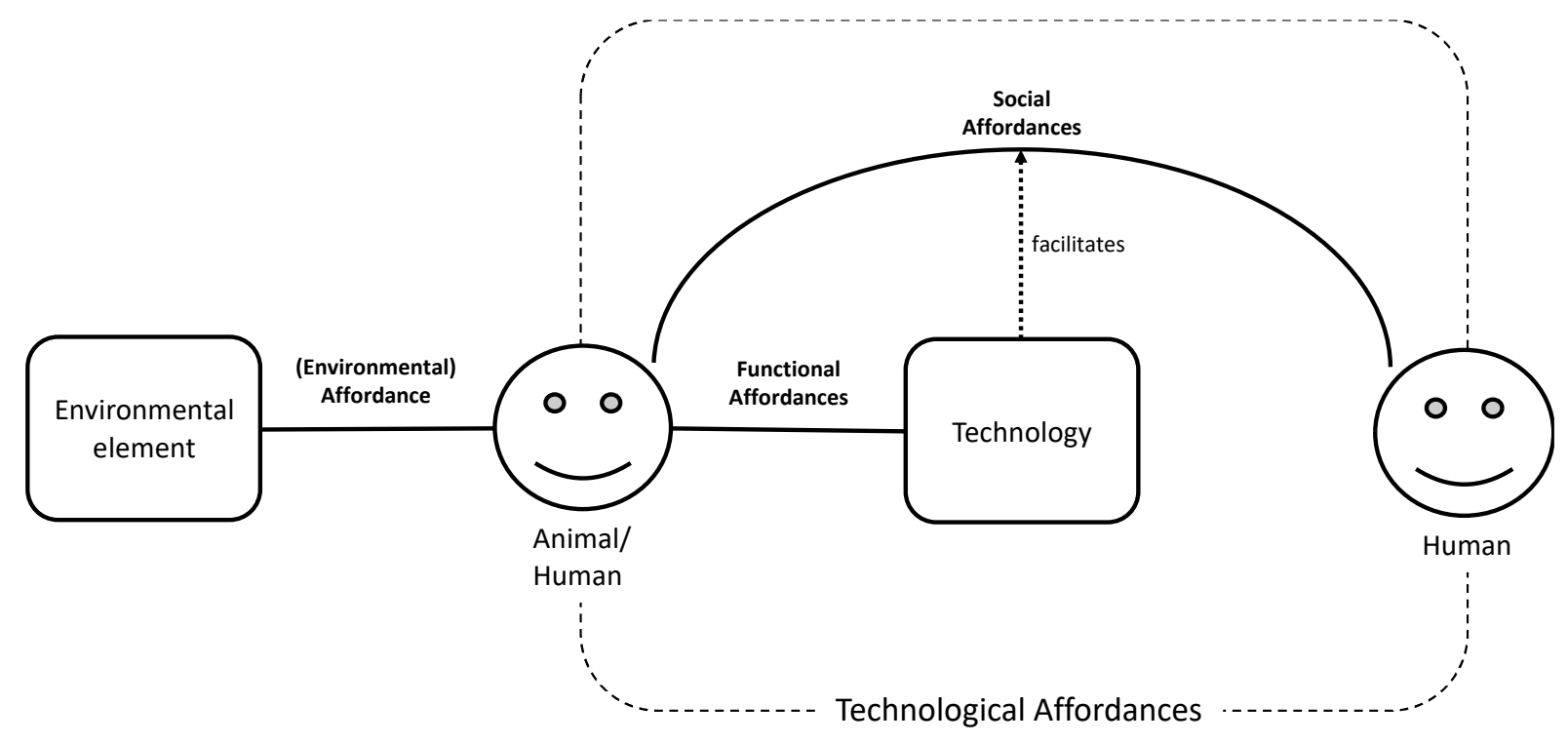

Figure 2: Different types of affordances 


\section{Figure 3}

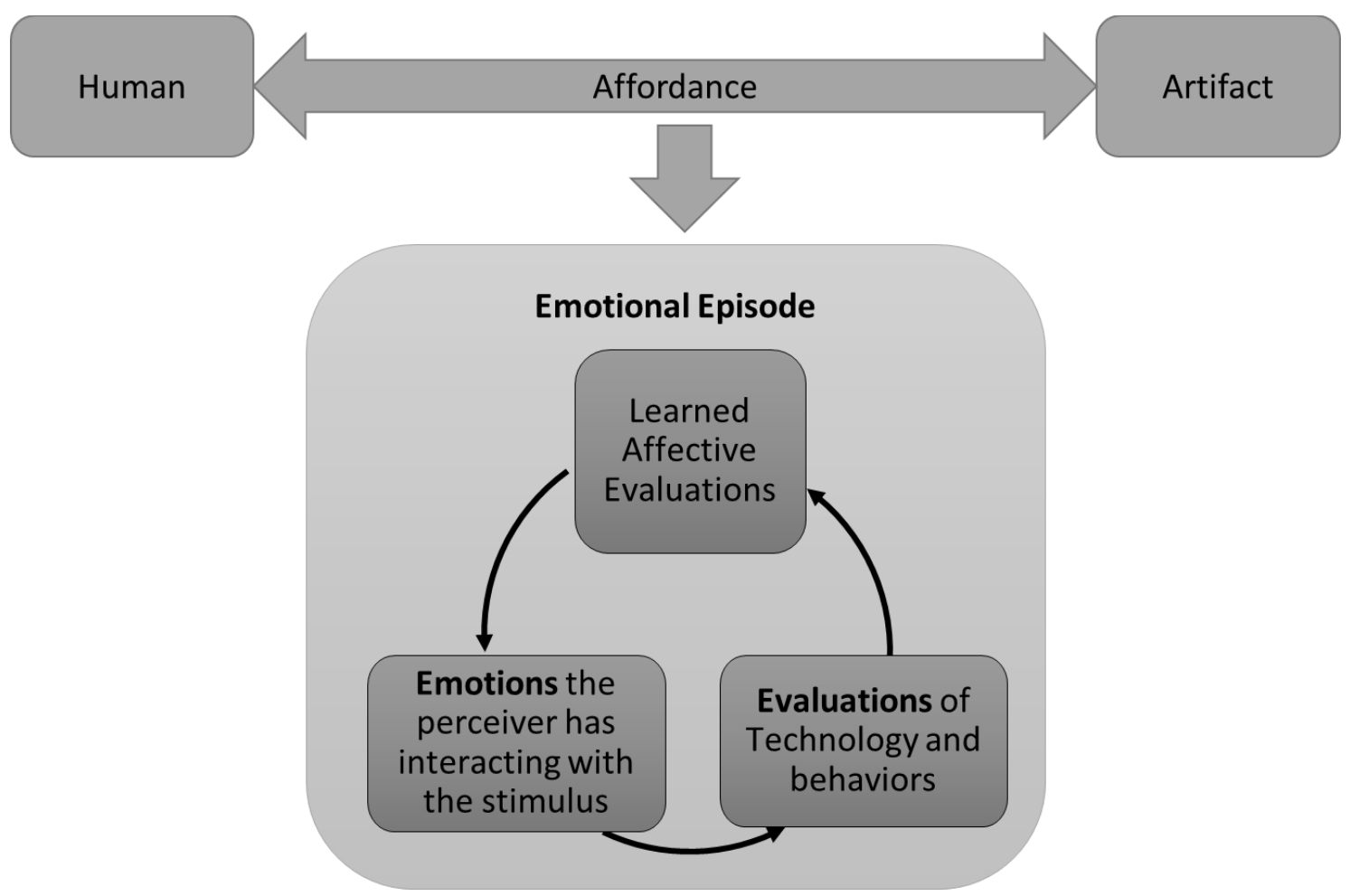

Figure 3: Conceptual Framework used to guide data analysis 


\section{Figure 4}

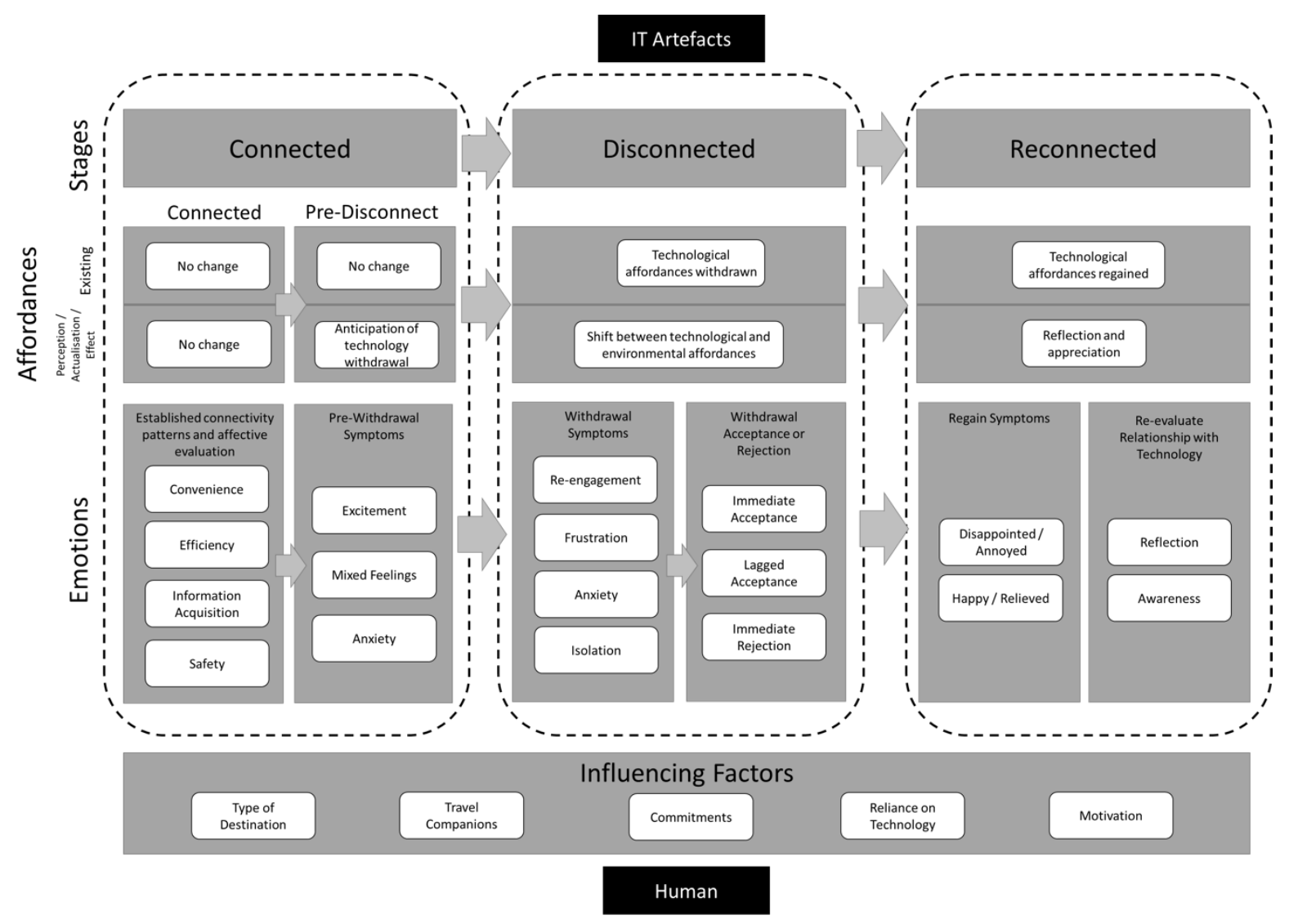

Figure 4: Disconnected Emotions Model (DEM) 


\section{Table 1}

\begin{tabular}{|l|l|}
\hline Construct & Definition \\
\hline Emotions the & The feelings the perceiver has, e.g. pleasure, satisfaction, anxiety, or mood. \\
\hline $\begin{array}{l}\text { Evaluations of } \\
\text { technology }\end{array}$ & $\begin{array}{l}\text { Affective evaluations of a particular technological object and behaviors. The meanings of } \\
\text { affective evaluations are between a person and a stimulus. Attitude towards technology. }\end{array}$ \\
\hline $\begin{array}{l}\text { Learned } \\
\text { affective }\end{array}$ & $\begin{array}{l}\text { A tendency to form certain affective evaluations based on prior experience or knowledge } \\
\text { toward technology. Long-lasting, learned over time, stored in memory, and not so easy to } \\
\text { evaluations }\end{array}$ \\
\hline
\end{tabular}

Table 1: Emotional episode model definitions (Zhang 2013, 260) 


\section{Table 2}

\begin{tabular}{|c|c|c|}
\hline Construct & Description & Literature \\
\hline $\begin{array}{l}\text { Affordance } \\
\text { Existence }\end{array}$ & $\begin{array}{l}\text { Affordances exist whether the animal cares about } \\
\text { them or not, and whether or not they are ever } \\
\text { actualized. }\end{array}$ & $\begin{array}{l}\text { Hutchby (2001), Stoffregen (2003) } \\
\text { Technology: } \\
\text { Leonardi (2013), Volkoff and Strong } \\
\text { (2013) }\end{array}$ \\
\hline $\begin{array}{l}\text { Affordance } \\
\text { Perception }\end{array}$ & $\begin{array}{l}\text { The range of affordances may not always be fully } \\
\text { and immediately perceptible. }\end{array}$ & $\begin{array}{l}\text { Chemero (2003), Hutchby (2001), } \\
\text { Stoffregen et al. (1999) } \\
\text { Technology: } \\
\text { Leonardi (2013), Hartson (2003), } \\
\text { Norman (1999) }\end{array}$ \\
\hline $\begin{array}{l}\text { Affordance } \\
\text { Actualization }\end{array}$ & $\begin{array}{l}\text { The action taken by animals as they take } \\
\text { advantage of one or more perceived affordances. }\end{array}$ & $\begin{array}{l}\text { Stoffregen (2003), Turvey (1992) } \\
\text { Technology: } \\
\text { Leonardi (2013), Markus and Silver } \\
\text { (2008), Strong et al. (2014), Volkoff } \\
\text { and Strong (2013), Tim et al. (2017) }\end{array}$ \\
\hline $\begin{array}{l}\text { Affordance } \\
\text { Effect }\end{array}$ & $\begin{array}{l}\text { Positive or negative effect generated from } \\
\text { affordance actualization. }\end{array}$ & $\begin{array}{l}\text { Technology: } \\
\text { Groshek and Tandoc (2017), Leonardi } \\
\text { (2013), Strong et al. (2014) }\end{array}$ \\
\hline
\end{tabular}

Table 2: Affordance types and their properties, modified from Bernhard, Recker, and BurtonJones (2013) and Pozzi, Pigni, and Vitari (2014) 
Table 3

\begin{tabular}{|c|c|c|c|c|c|c|c|c|}
\hline Pseudonym & Sex & Age & Travel From & Travel To & $\begin{array}{l}\text { Total } \\
\text { Trip }\end{array}$ & $\begin{array}{l}\text { Disconnect } \\
\text { Days }\end{array}$ & Diary & Interview \\
\hline \multirow[t]{2}{*}{ James } & $\mathrm{M}$ & $\begin{array}{l}35- \\
40\end{array}$ & Norwich, UK & Ely, UK & 1 & 1 & $\mathrm{X}$ & \\
\hline & & & Norwich, UK & $\begin{array}{l}\text { Vienna, } \\
\text { Austria }\end{array}$ & 4 & 3 & $X$ & \\
\hline \multirow[t]{2}{*}{ Thomas } & $\mathrm{M}$ & $\begin{array}{l}25- \\
30\end{array}$ & Norwich, UK & Ely, UK & 1 & 1 & $X$ & \\
\hline & & & Norwich, UK & $\begin{array}{l}\text { Vienna, } \\
\text { Austria }\end{array}$ & 4 & 3 & $X$ & \\
\hline John & $\mathrm{M}$ & $50+$ & $\begin{array}{l}\text { Manchester, } \\
\text { UK }\end{array}$ & Hebrides, UK & 13 & 7 & $X$ & \\
\hline Richard & $\mathrm{M}$ & $\begin{array}{l}35- \\
40\end{array}$ & $\begin{array}{l}\text { Arlington, } \\
\text { Virginia, } \\
\text { USA }\end{array}$ & $\begin{array}{l}\text { Orleans, } \\
\text { Massachusetts } \\
\text {, USA }\end{array}$ & 6 & 1 & $X$ & \\
\hline Frank & $\mathrm{M}$ & $\begin{array}{l}40- \\
45\end{array}$ & $\begin{array}{l}\text { Arlington, } \\
\text { Virginia, } \\
\text { USA }\end{array}$ & $\begin{array}{l}\text { Orleans, } \\
\text { Massachusetts } \\
\text {, USA }\end{array}$ & 6 & 1 & $X$ & $\mathrm{X}$ \\
\hline Youngqi & $\mathrm{F}$ & $\begin{array}{l}30- \\
35\end{array}$ & $\begin{array}{l}\text { Xiamen, } \\
\text { China }\end{array}$ & $\begin{array}{l}\text { Neuschwanste } \\
\text { in, Germany }\end{array}$ & 10 & 2 & $X$ & $\mathrm{X}$ \\
\hline Zhenpeng & $\mathrm{M}$ & $\begin{array}{l}25- \\
30\end{array}$ & $\begin{array}{l}\text { Guangzhou } \\
\text { China }\end{array}$ & Macau, China & 2 & 0.5 & & $\mathrm{X}$ \\
\hline \multirow[t]{2}{*}{ Billy } & $\mathrm{M}$ & $\begin{array}{l}20- \\
25\end{array}$ & $\begin{array}{l}\text { Melbourne, } \\
\text { Australia }\end{array}$ & $\begin{array}{l}\text { Switzerland } \\
\text { and France }\end{array}$ & 3 & 1 & $X$ & $\mathrm{X}$ \\
\hline & & & $\begin{array}{l}\text { Melbourne, } \\
\text { Australia }\end{array}$ & $\begin{array}{l}\text { Berlin, } \\
\text { Germany }\end{array}$ & 3 & 1 & $X$ & $\mathrm{X}$ \\
\hline Anita & $\mathrm{F}$ & $\begin{array}{l}25- \\
30\end{array}$ & $\begin{array}{l}\text { Edinburgh, } \\
\text { UK }\end{array}$ & $\begin{array}{l}\text { Cerveny } \\
\text { Klastor, } \\
\text { Slovakia }\end{array}$ & 1.5 & 1.5 & $X$ & \\
\hline Sally & $\mathrm{F}$ & $\begin{array}{l}30- \\
35\end{array}$ & $\begin{array}{l}\text { Auckland, } \\
\text { NZ }\end{array}$ & $\begin{array}{l}\text { Queenstown, } \\
\text { NZ }\end{array}$ & 3 & 1 & $X$ & $\mathrm{X}$ \\
\hline Jiaying & $\mathrm{F}$ & $\begin{array}{l}35- \\
40\end{array}$ & $\begin{array}{l}\text { Portsmouth, } \\
\text { UK }\end{array}$ & $\begin{array}{l}\text { Copenhagen, } \\
\text { Denmark }\end{array}$ & 3 & 2 & $X$ & $\mathrm{X}$ \\
\hline Lisa & $\mathrm{F}$ & $\begin{array}{l}25- \\
30 \\
\end{array}$ & $\begin{array}{l}\text { Munich, } \\
\text { Germany }\end{array}$ & $\begin{array}{l}\text { Taipei, } \\
\text { Taiwan }\end{array}$ & 3 & 3 & $X$ & \\
\hline Heike & $\mathrm{F}$ & $\begin{array}{l}25- \\
30 \\
\end{array}$ & $\begin{array}{l}\text { Innsbruck, } \\
\text { Austria }\end{array}$ & Cuba & 13 & 13 & & $\mathrm{X}$ \\
\hline Susan & $\mathrm{F}$ & $\begin{array}{l}30- \\
35\end{array}$ & $\begin{array}{l}\text { Auckland, } \\
\text { NZ }\end{array}$ & Tonga & 5 & 5 & & $\mathrm{X}$ \\
\hline Sean & $\mathrm{M}$ & $\begin{array}{l}30- \\
35\end{array}$ & $\begin{array}{l}\text { Auckland, } \\
\text { NZ }\end{array}$ & Tonga & 5 & 5 & & $\mathrm{X}$ \\
\hline Stephan & $\mathrm{M}$ & $\begin{array}{l}25- \\
30 \\
\end{array}$ & $\begin{array}{l}\text { Innsbruck, } \\
\text { Austria }\end{array}$ & Cuba & 13 & 13 & & $\mathrm{X}$ \\
\hline Rory & $\mathrm{F}$ & $\begin{array}{l}30- \\
35\end{array}$ & $\begin{array}{l}\text { Auckland, } \\
\text { NZ }\end{array}$ & $\begin{array}{l}\text { Abel Tasman } \\
\text { National Park, } \\
\text { NZ } \\
\end{array}$ & 4 & 3 & & $\mathrm{X}$ \\
\hline Nico & $\mathrm{M}$ & $\begin{array}{l}30- \\
35\end{array}$ & $\begin{array}{l}\text { Auckland, } \\
\text { NZ }\end{array}$ & $\begin{array}{l}\text { Abel Tasman } \\
\text { National Park, } \\
\text { NZ } \\
\end{array}$ & 4 & 3 & & $\mathrm{X}$ \\
\hline Dough & $\mathrm{M}$ & $\begin{array}{l}30- \\
35\end{array}$ & $\begin{array}{l}\text { Auckland, } \\
\text { NZ }\end{array}$ & $\begin{array}{l}\text { Abel Tasman } \\
\text { National Park, } \\
\text { NZ }\end{array}$ & 4 & 3 & & $\mathrm{X}$ \\
\hline Steven & $\mathrm{M}$ & $\begin{array}{l}30- \\
35\end{array}$ & $\begin{array}{l}\text { Auckland, } \\
\text { NZ }\end{array}$ & Cook Islands & 7 & 7 & & $\mathrm{X}$ \\
\hline
\end{tabular}




\begin{tabular}{|l|l|l|l|l|l|l|l|l|}
\hline Larissa & F & $\begin{array}{l}25- \\
30\end{array}$ & $\begin{array}{l}\text { Innsbruck, } \\
\text { Austria }\end{array}$ & Kiev, Ukraine & 14 & 0 & & X \\
\hline Lauren & F & $\begin{array}{l}25- \\
30\end{array}$ & $\begin{array}{l}\text { Auckland, } \\
\text { NZ }\end{array}$ & Fiji & 14 & $3-4$ & & X \\
\hline Noah & M & $\begin{array}{l}25- \\
30\end{array}$ & $\begin{array}{l}\text { Auckland, } \\
\text { NZ }\end{array}$ & Fiji & 14 & $3-4$ & & X \\
\hline Bailey & M & $\begin{array}{l}20- \\
25\end{array}$ & Norwich, UK & Spain & 35 & 5.5 & X & \\
\hline
\end{tabular}




\section{Table 4}

\begin{tabular}{|l|l|}
\hline Affordance & Emotional Episode \\
\hline Affordance withdraw & Learned effective evaluation \\
\hline Affordance regain & Emotional response towards disconnecting \\
\hline Technological affordances & Emotional response towards reconnecting \\
\hline Environmental affordances & Evaluation of disconnected experience \\
\hline Affordance existence & \\
\hline Affordance Perception & \\
\hline Affordance actualization & \\
\hline Affordance effect & \\
\hline
\end{tabular}

Table 4: start list of provisional codes. 


\section{Table 5}

\begin{tabular}{|c|c|}
\hline Quote & Analysis \\
\hline $\begin{array}{l}\text { "I'm (person) sitting on the train now. Usually at this } \\
\text { time I would check details of the train on my phone } \\
\text { (technological stimulus) to be sure of the correct } \\
\text { train, departure time, platform, how many stops, } \\
\text { arrival time (affordance loss). I did write some of } \\
\text { this down before I left home, however I'm fighting } \\
\text { the urge to check my phone. What if I wrote } \\
\text { something down wrong (affective response)?" }\end{array}$ & $\begin{array}{l}\text { Technological Stimulus: Phone } \\
\text { Person: The participant } \\
\text { Affordance(s): Train information } \\
\text { Affective Response: Anxiety } \\
\text { Other information: learned affective evaluations } \\
\text { (normal behavior with technology), withdrawal } \\
\text { symptoms (anxiety), pre-disconnect planning. }\end{array}$ \\
\hline $\begin{array}{l}\text { "Finding a restaurant stressed me out a little } \\
\text { (affective response). Usually I would check online } \\
\text { (on my phone) (technological stimulus) the location } \\
\text { of restaurants (affordance loss) but we just had to } \\
\underline{\text { walk (person) around until we found one. I didn't }} \\
\text { even know what direction to walk. I was looking for } \\
\text { a sign to say "restaurants this way". I find I really } \\
\text { have to pay more attention to signs now." }\end{array}$ & $\begin{array}{l}\text { Technological Stimulus: Phone } \\
\text { Person: The participant and companion } \\
\text { Affordance(s): Technological: location information } \\
\text { (loss). Environmental: more aware of surroundings } \\
\text { (gained) } \\
\text { Affective Response: Stress } \\
\text { Other information: looking for additional } \\
\text { information in the surrounding environment } \\
\text { (signage), rely on environmental affordances. }\end{array}$ \\
\hline $\begin{array}{l}\text { "This morning I (person) woke up and really felt I } \\
\text { was missing (affective response) my phone } \\
\text { (technological stimulus). Usually before I get out of } \\
\text { bed, I will check my emails and Facebook and the } \\
\underline{\text { news (affordance loss). But I just lay there staring at }} \\
\underline{\text { the wall (affective response). I went to breakfast and }} \\
\underline{\text { saw others using their phones and I felt envious of }} \\
\underline{\text { them (affective response). When I eat alone, I would }} \\
\underline{\text { usually look at Facebook or 9Gag while eating }} \\
\text { (affordance loss). I felt very isolated and alone }\end{array}$ & $\begin{array}{l}\text { Technological Stimulus: Phone } \\
\text { Person: The participant, and other unknown } \\
\text { connected people nearby } \\
\text { Affordance(s): Technological: loss of information } \\
\text { (emails, news, and social connections). Social: } \\
\text { listening to other conversations (gained) } \\
\text { Affective Response: missing, envious, isolated, } \\
\text { alone, staring at the wall (withdrawal symptoms) } \\
\text { Other information: learned effective behaviors, } \\
\text { (normal behavior with technology), jealousy of }\end{array}$ \\
\hline
\end{tabular}


(affective response). So, I tried to listen to other people's conversations, but the majority were not in

English. There were 2 French guys, so I was trying to guess what they were saying." connected people, pay more attention to other people around, listen to their conversations to fill the gap

left by technology, evaluation of disconnection (isolated and alone).

Table 5: illustrative quotes and data analysis of emerging themes 


\section{Appendix 1}

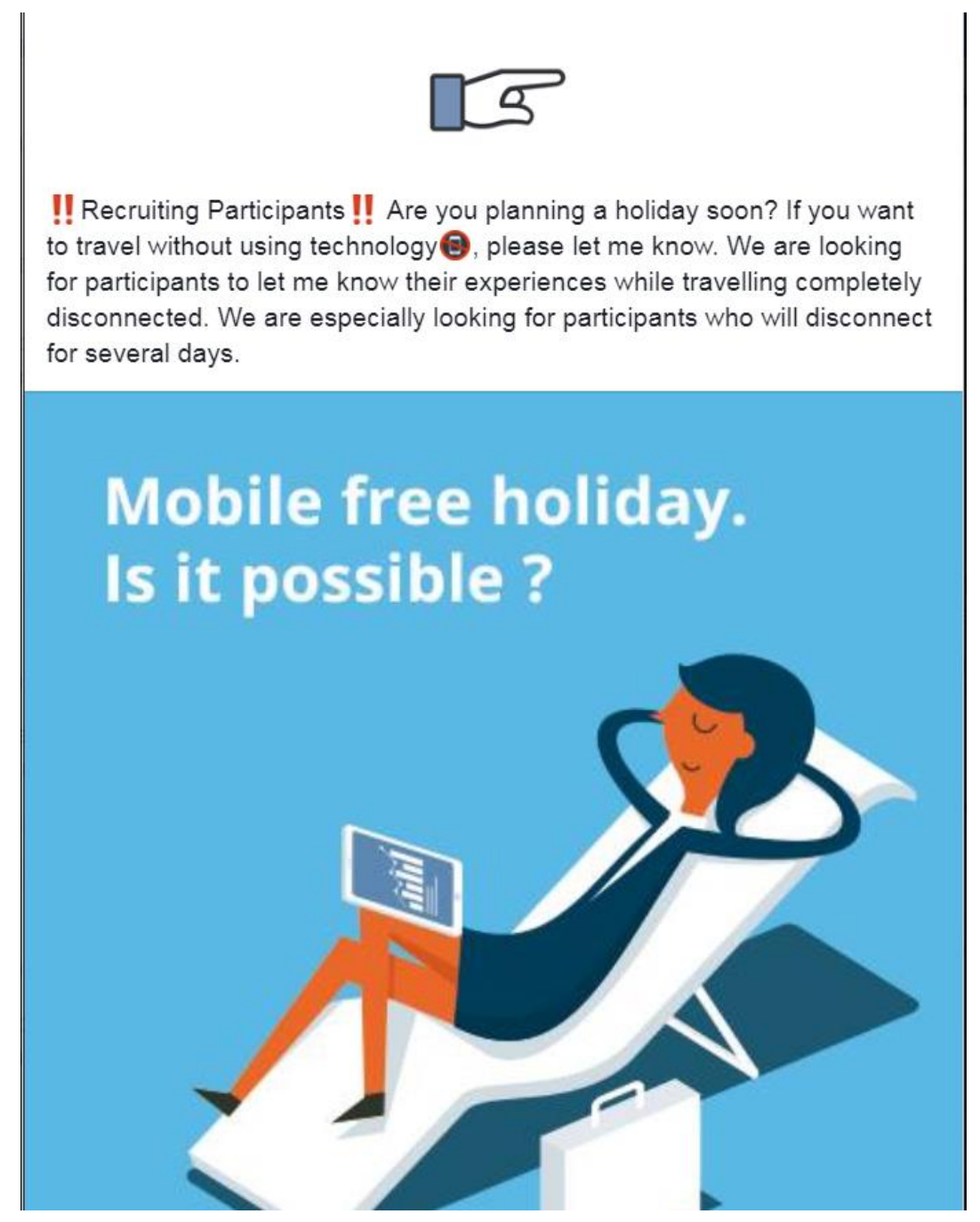

Facebook Post 


\section{Appendix 2}

Instructions for participants (diaries), and key topics for interviews:

Total Days of Trip: what was your total trip duration?

Total Days without Technology: how many days (including part days) did you not use technology?

Where From/To: where did you travel from and to?

What mode(s) of transportation did you use? E.g. bus, car, train, plane, bike.

\section{Your usual use of technology while travelling:}

How do you usually use technology while you are travelling?

Before the Trip: Knowing that you won't be using technology, how did this affect the planning of the trip? Note down things you do differently as well as how do you feel before the departure.

During the Trip: How is your experience during the trip? For example, using maps, public transport, finding restaurants etc. Please note down your feelings as detailed as possible. (In what occasion and how do you feel at that moment?). What did you do differently?

Was there any occasion where you had to use some form of technology? You do not have to go without technology for the entire trip. If you feel at some stage you cannot do it anymore, then please use technology again. However, we would like to know why this happened, and what motivated you to use the technology again.

After the trip: What are your reflections afterwards on your experience of not using technology during your trip? What are the main differences from trips with technologies? 